\title{
Fuzzy sliding mode control of doubly-fed induction generator driven by wind turbine
}

\author{
M. Benmeziane ${ }^{1}$, S. Zebirate ${ }^{1,2}$, A. Chaker ${ }^{1}$, Z. Boudjema $^{3}$ \\ ${ }^{1}$ SCAMRE Laboratory, Maurice Audin National Polytechnic School of Oran, ENPO, Oran, Algeria \\ ${ }^{2}$ IMSI, University of Oran 2 Mohamed BENAHMED, Oran, Algeria \\ ${ }^{3}$ Department of Electrical Engineering, University of Sidi Bel-Abbes, Algeria
}

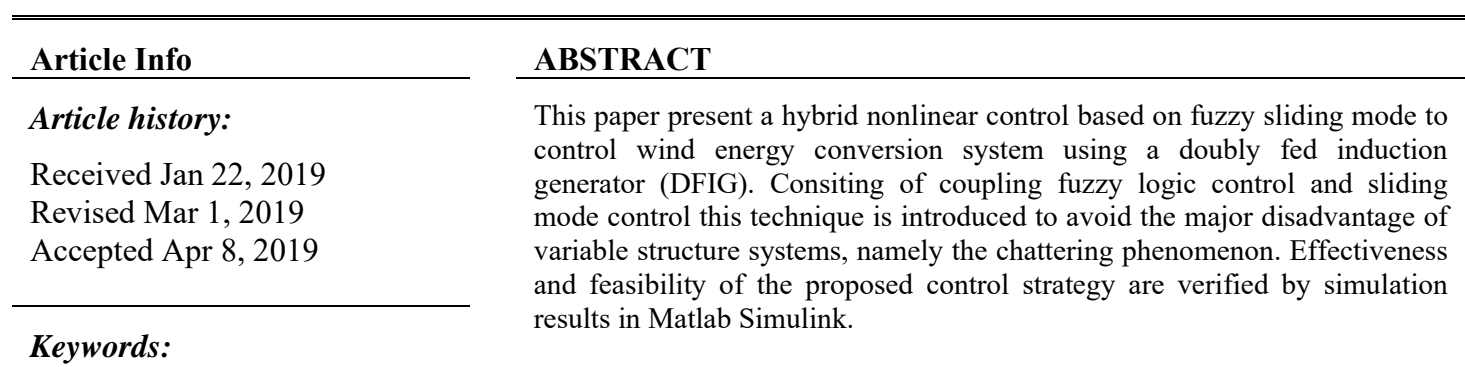

Doubly fed induction generator

Fuzzy logic

Nonlinear controller

Power control

Sliding mode controller

\section{Corresponding Author:}

Meriem Benmeziane, Department of Electrical Engineering, National Polytechnic School of Oran, Maurice Audin, Algeria.

Email: m.benmeziane@yahoo.fr

\section{INTRODUCTION}

Wind power has become increasingly popular because of the increasing difficulty of the environmental pollution and the greenhouse effect. Huge efforts have been made in promoting the wind energy conversion system, to reduce costs, increase reliability and robustness [1]. Variable speed operation of wind turbine is usually used to provide energy with best efficiency. Those based on doubly fed induction generators are widely used especially in high power fields, thanks to different advantages it presents namely: reducing the size of the converter, operating in a large game of speed, and the possibility of controlling independently the generated active and reactive powers [2].

A Doubly Fed Induction Generator (DFIG) is an electrical asynchronous three-phase machine with open rotor windings which can be fed by external voltages. The typical connection scheme of this machine is reported in Figure 1. The stator windings are directly connected to the line grid, while the rotor windings are controlled by means of an inverter [3].

Many control techniques are used to control doubly fed induction generator. Zerzouri et al. have tried to improve the performance of a DFIG wind energy conversion system; they have proposed the vector control with the PI controller to decouple the active and reactive power of the stator. They have used a single PI in each control loop, but this control has oscillations, exceedances, and the decoupling is not fully maintained [4]. Poitiers et al. have used the RST polynomial controller, they have found that the RST control is more robust than the PI control compared to the rotor resistance variation, but the oscillations remain apparent [5]. 
The sliding mode control (SMC) achieves robust control by adding a discontinuous control signal across the sliding surface, satisfying the sliding condition [6]. In [7], a dynamical sliding mode power control structure is suggested for DFIG. In [8], the SMC technique is used to control the rotational speed in the rotor side as well as the dc-link voltage in the grid side of a wind energy conversion system; a model predictive control based SMC is proposed to control a three-phase grid-connected converter and the grid current total harmonic distortion and the switching losses are largely mitigated in [9].

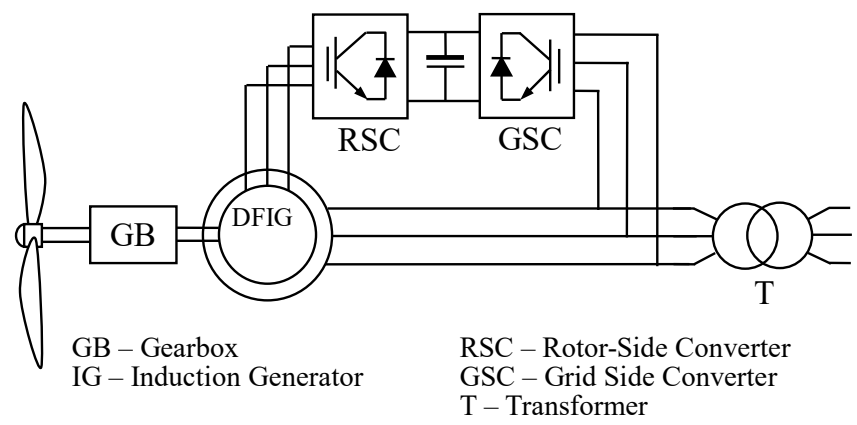

Figure 1. Configuration of DFIG- Wind Turbine

The SMC has a major inconvenience which the chattering effect is created by the discontinuous part of control. Chattering causes several damages to the mechanical components. To treat these difficulties and improve the performances, different methods were proposed such as by replacing the sign function with saturation [10] or using Quasi-SMC and fuzzy mathematics [11]. In [12] an optimized sliding mode controls (SMC) strategy to maximize existence region for single-phase dynamic voltage restorers. It is shown analytically that there exists an optimum sliding coefficient which enlarges the existence region of the sliding mode to its maximum. Also, it is pointed out that the optimum sliding coefficient improves the dynamic response. In [13] the author proposes a SMC control strategy which combines a switched policy with a timebased adaptation of the control gain, thereby allowing to effectively dealing with a very conservative prior knowledge of the upper bounds on the uncertainties, which usually leads to a large control authority, and related performance degradation in [14].

The fuzzy logic controller is a powerful tool for controlling complex processes, without the need of a detailed mathematical model of the system. In fact, this technique of control has been used to solve the unknown parameters variations or to remove the effect of nonlinearity; it has been successfully applied to electromagnetic motors control and the fuzzy model of a plant is very easy to apply [15].

In this paper the sliding mode controller is combined with Fuzzy Logic (FL) to form a fuzzy sliding mode controller (FSMC) to reduce the chattering phenomenon and improve time of reponse [16]. Design, implementation, analysis and comparison between the classical sliding mode control (SMC) and the hybrid fuzzy sliding mode control (FSMC) is presented with simulation in Matlab Simulink.

\section{RESEARCH METHOD}

\subsection{DFIG model}

The Doubly Fed Induction Generator DFIG model using Park transformation is as (1) [17]:

$$
\left\{\begin{array}{l}
\mathrm{V}_{\mathrm{ds}}=\mathrm{R}_{\mathrm{s}} \mathrm{I}_{\mathrm{ds}}+\frac{\mathrm{d}}{\mathrm{dt}} \varphi_{\mathrm{ds}}-\omega_{\mathrm{s}} \varphi_{\mathrm{qs}} \\
\mathrm{V}_{\mathrm{qs}}=\mathrm{R}_{\mathrm{s}} \mathrm{I}_{\mathrm{qs}}+\frac{\mathrm{d}}{\mathrm{dt}} \varphi_{\mathrm{qs}}+\omega_{\mathrm{s}} \varphi_{\mathrm{ds}} \\
\mathrm{V}_{\mathrm{dr}}=\mathrm{R}_{\mathrm{r}} \mathrm{I}_{\mathrm{dr}}+\frac{\mathrm{d}}{\mathrm{dt}} \varphi_{\mathrm{dr}}-\omega_{\mathrm{r}} \varphi_{\mathrm{qr}} \\
\mathrm{V}_{\mathrm{qr}}=\mathrm{R}_{\mathrm{r}} \mathrm{I}_{\mathrm{qr}}+\frac{\mathrm{d}}{\mathrm{dt}} \varphi_{\mathrm{qr}}+\omega_{\mathrm{r}} \varphi_{\mathrm{dr}}
\end{array}\right.
$$

The flux can be expressed as (2):

Fuzzy sliding mode control of doubly-fed induction generator driven by wind turbine (M. Benmeziane) 


$$
\left\{\begin{array}{l}
\psi_{d s}=L_{s} I_{d s}+M I_{d r} \\
\psi_{q s}=L_{s} I_{q s}+M I_{q r} \\
\psi_{d r}=L_{r} I_{d r}+M I_{d s} \\
\psi_{q r}=L_{r} I_{q r}+M I_{q s}
\end{array}\right.
$$

The stator and rotor angular velocities are linked by the following relation: $\omega_{s}=\omega+\omega_{r}$. The mechanical equation is given by (3):

$$
C_{e m}=C_{r}+J \frac{d \Omega}{d t}+f \Omega
$$

Where the electromagnetic torque $C_{e m}$ can be written as a function of stator fluxes and rotor currents (4):

$$
C_{e m}=p \frac{M}{L_{s}}\left(\varphi_{q s} I_{d r}-\varphi_{d s} I_{q r}\right)
$$

\subsection{Active and reactive power control}

To easily control the production of electricity from wind, we will achieve an independent control of active and reactive power by the stator flux orientation as shown on Figure 2 [18].

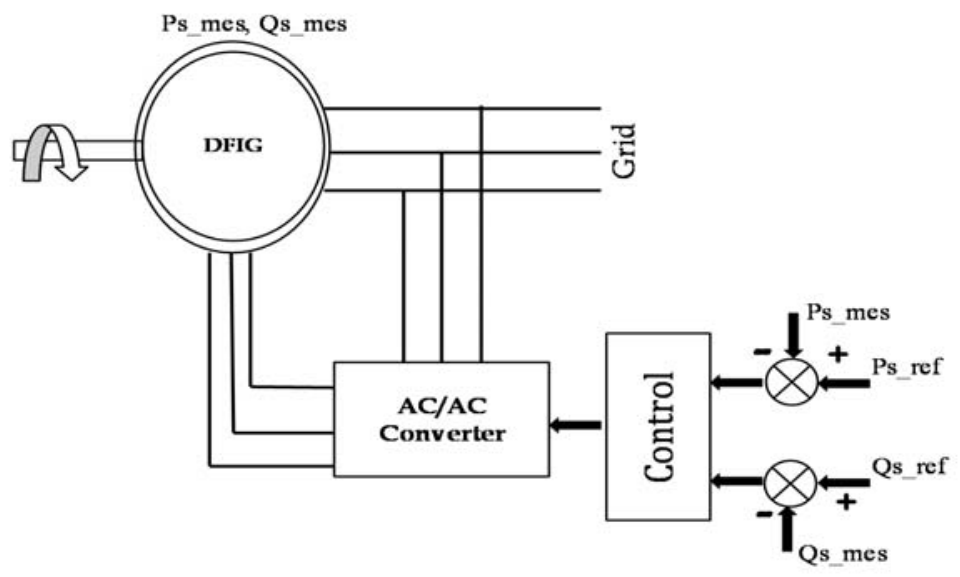

Figure 2. Power control between the stator and network

To realize a stator active and reactive power vector control, we choose a d-q reference-frame synchronized with the stator flux [19]. By setting null the quadratic component of the stator flux, we have (5):

$$
\varphi_{d s}=\varphi_{s} \quad \text { and } \quad \varphi_{q s}=0
$$

and the electromagnetic torque can be expressed (6):

$$
C_{e m}=-p \frac{M}{L_{s}} I_{q r} \varphi_{d s}
$$

By substituting (6) in (3), the following rotor flux equations are obtained: 


$$
\left\{\begin{array}{l}
\varphi_{s}=L_{s} I_{d s}+M I_{d r} \\
0=L_{s} I_{q s}+M I_{q r}
\end{array}\right.
$$

Moreover, the stator voltage equations are reduced $\mathrm{t}(8) \mathrm{o}$ :

$$
\left\{\begin{array}{l}
V_{d s}=0 \\
V_{q s}=\omega_{s} \varphi_{s}
\end{array}\right.
$$

By supposing that the electrical supply network is stable, having for simple voltage $V_{s}$ that led to a stator flux $\varphi_{s}$ constant. This consideration associated with (7) shows that the electromagnetic torque only depends on the $q$-axis rotor current component.

Using (8), a relation between the stator and rotor currents can be established (9)[20]:

$$
\left\{\begin{array}{l}
I_{d s}=-\frac{M}{L_{s}} I_{d r}+\frac{\varphi_{s}}{L_{s}} \\
I_{q s}=-\frac{M}{L_{s}} I_{q r}
\end{array}\right.
$$

The stator active and reactive powers are written(10):

$$
\left\{\begin{array}{l}
P_{s}=V_{d s} I_{d s}+V_{q s} I_{q s} \\
Q_{s}=V_{q s} I_{d s}-V_{d s} I_{q s}
\end{array}\right.
$$

By using (1), (2), (4) and (10), the statoric active and reactive power, the rotoric fluxes and voltages can be written versus rotoric currents as:

$$
\begin{aligned}
& \left\{\begin{array}{l}
P_{s}=\frac{\omega_{s} \varphi_{s} M}{L_{s}} I_{q r} \\
Q_{s}=-\frac{\omega_{s} \varphi_{s} M}{L_{s}} I_{d r}+\frac{\omega_{s} \varphi_{s}^{2}}{L_{s}}
\end{array}\right. \\
& \left\{\begin{array}{l}
\varphi_{d r}=\left(L_{r}-\frac{M^{2}}{L_{s}}\right) I_{d r}+\frac{M \varphi_{s}}{L_{s}} \\
\varphi_{q r}=\left(L_{r}-\frac{M^{2}}{L_{s}}\right) I_{q r}
\end{array}\right. \\
& \left\{\begin{array}{l}
\mathrm{V}_{\mathrm{dr}}=\mathrm{R}_{\mathrm{r}} \mathrm{I}_{\mathrm{dr}}+\left(\mathrm{L}_{\mathrm{r}}-\frac{\mathrm{M}^{2}}{\mathrm{~L}_{\mathrm{s}}}\right) \frac{\mathrm{dI} \mathrm{dr}}{\mathrm{dt}}-\mathrm{g} \omega_{\mathrm{s}}\left(\mathrm{L}_{\mathrm{r}}-\frac{\mathrm{M}^{2}}{\mathrm{~L}_{\mathrm{s}}}\right) \mathrm{I}_{\mathrm{qr}} \\
\mathrm{V}_{\mathrm{qr}}=\mathrm{R}_{\mathrm{r}} \mathrm{I}_{\mathrm{qr}}+\left(\mathrm{L}_{\mathrm{r}}-\frac{\mathrm{M}^{2}}{\mathrm{~L}_{\mathrm{s}}}\right) \frac{\mathrm{dI} \mathrm{dr}}{\mathrm{dt}}+\mathrm{g} \omega_{\mathrm{s}}\left(\mathrm{L}_{\mathrm{r}}-\frac{\mathrm{M}^{2}}{\mathrm{~L}_{\mathrm{s}}}\right) \mathrm{I}_{\mathrm{dr}}+\mathrm{g} \omega_{\mathrm{s}} \frac{\mathrm{M} \varphi_{\mathrm{s}}}{\mathrm{L}_{\mathrm{s}}}
\end{array}\right.
\end{aligned}
$$

In steady state, the second derivative terms of the two equations in (14) are nil. We can thus write:

$$
\left\{\begin{array}{l}
V_{d r}=R_{r} I_{d r}-g \omega_{s}\left(L_{r}-\frac{M^{2}}{L_{s}}\right) I_{q r} \\
V_{q r}=R_{r} I_{q r}+g \omega_{s}\left(L_{r}-\frac{M^{2}}{L_{s}}\right) I_{d r}+g \omega_{s} \frac{M \varphi_{s}}{L_{s}}
\end{array}\right.
$$

The third term, which constitutes cross-coupling terms, can be neglected because of their small influence. These terms can be compensated by an adequate synthesis of the regulators in the control loops [20]. Figure 3 shows the Power Control of DFIG.

Fuzzy sliding mode control of doubly-fed induction generator driven by wind turbine (M. Benmeziane) 


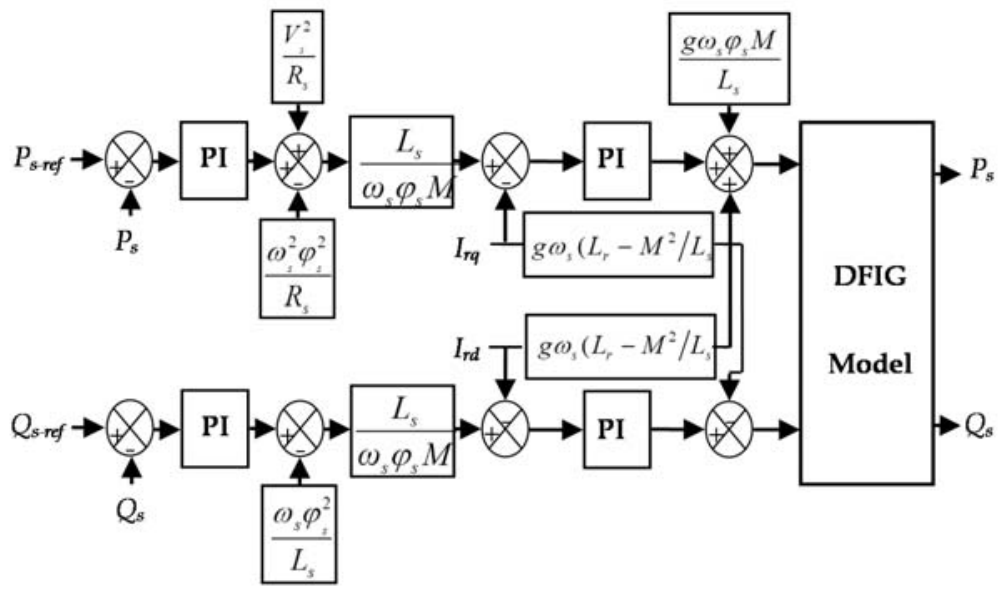

Figure 3. Power control of DFIG

\subsection{Sliding mode control}

The sliding mode technique is developed from variable structure control to solve the disadvantages of other designs of nonlinear control systems. The sliding mode is a technique to adjust feedback by previously defining a surface. The system which is controlled will be forced to that surface, then the behaviour of the system slides to the desired equilibrium point. The main feature of this control is that we only need to drive the error to a "switching surface". When the system is in "sliding mode", the system behaviour is not affected by any modelling uncertainties and/or disturbances. The design of the control system will be demonstrated for a nonlinear system presented in the canonical form(15) [21]:

$$
\dot{x}=f(x, t)+B(x, t) U(x, t), x \in R^{n}, U \in R^{m}, \operatorname{ran}(B(x, t))=m
$$

With control in the sliding mode, the goal is to keep the system motion on the manifold $S$, which is defined as:

$$
\begin{aligned}
& S=\{x: e(x, t)=0\} \\
& e=x^{d}-x
\end{aligned}
$$

Here $e$ is the tracking error vector, $x^{d}$ is the desired state, $x$ is the state vector. The control input $U$ has to guarantee that the motion of the system described in (17) is restricted to belong to the manifold $S$ in the state space. The sliding mode control should be chosen such that the candidate Lyapunov function satisfies the Lyapunov stability criteria [22]:

$$
\begin{aligned}
& \vartheta=\frac{1}{2} S(x)^{2} \\
& \dot{\vartheta}=S(x) \dot{S}(x)
\end{aligned}
$$

This can be assured for:

$$
\dot{\vartheta}=-\eta|S(x)|
$$

Here $\eta$ is strictly positive. Essentially, equation (18) states that the squared "distance" to the surface, measured by $e(x)^{2}$, decreases along all system trajectories. Therefore (19), (20) satisfy the Lyapunov condition. With selected Lyapunov function the stability of the whole control system is guaranteed. The control function will satisfy reaching conditions in the following form [23]: 


$$
U^{c o m}=U^{e q}+U^{n}
$$

Here $U^{c o m}$ is the control vector, $U^{e q}$ is the equivalent control vector, $U^{n}$ is the correction factor and must be calculated so that the stability conditions for the selected control are satisfied.

$$
U^{n}=K \operatorname{sat}(S(x))
$$

Where $\operatorname{sat}(S(x))$ is the proposed saturation function, $K$ is the controller gain.

In this paper we propose the Slotine method [24]:

$$
S(X)=\left(\frac{\mathrm{d}}{\mathrm{dt}}+\xi\right)^{n-1} e
$$

Here, $e$ is the tracking error vector, $\xi$ is a positive coefficient and $n$ is the relative degree.

\subsection{Application of SMC to the DFIG}

In our study, we choose the error between the measured and references stator powers as sliding mode surfaces, so we can write the following expression:

$$
\left\{\begin{array}{l}
S_{d}=P_{S-r e f}-P_{S} \\
S_{q}=Q_{S-r e f}-Q_{S}
\end{array}\right.
$$

The first order derivate of (24), gives:

$$
\left\{\begin{array}{l}
\dot{S}_{d}=\dot{P}_{S-r e f}-\dot{P}_{S} \\
\dot{S}_{q}=\dot{Q}_{S-r e f}-\dot{Q}_{S}
\end{array}\right.
$$

Replacing the powers in (25) by their expressions given in (11), one obtains:

$$
\left\{\begin{array}{l}
\dot{S}_{1}=\dot{P}_{S-r e f}-\frac{\omega_{s} \psi_{s} M}{L_{s}} \dot{I}_{q r} \\
\dot{S}_{2}=\dot{Q}_{S-r e f}+\frac{\omega_{s} \psi_{s} M}{L_{s}} \dot{I}_{d r}-\frac{\omega_{s} \psi_{s}{ }^{2}}{L_{s}}
\end{array}\right.
$$

$V_{d r}$ and $V_{q r}$ will be the two components of the control vector used to constraint the system to converge to $S_{d q}=0$. The control vector $V_{d q e q}$ is obtained by imposing $\dot{S}_{d q}=0$ so the equivalent control components are given by the following relation:

$$
V_{\text {eqdq }}=\left[\begin{array}{l}
-\frac{L_{s}\left(L_{r}-\frac{M^{2}}{L_{s}}\right)}{\omega_{s} \psi_{s} M} \dot{Q}_{s}^{*}+R_{r} I_{d r}-\left(L_{r}-\frac{M^{2}}{L_{s}}\right) g \omega_{s} I_{q r}+\frac{\left(L_{r}-\frac{M^{2}}{L_{s}}\right) \psi_{s}}{M} \\
\frac{L_{s}}{\omega_{s} \psi_{s} M} \dot{P}_{s}^{*}+R_{r} I_{q r}-\left(L_{r}-\frac{M^{2}}{L_{s}}\right) g \omega_{s} I_{d r}+\frac{g \omega_{s} \psi_{s} M}{L_{s}}
\end{array}\right]
$$

To obtain good performances, dynamic and commutations around the surfaces, the control vector is imposed as follows:

$$
V_{d q}=V_{e q d q}+\mathrm{K} \cdot \operatorname{sat}\left(S_{d q}\right)
$$

The SM will exist only if the following condition is met:

$$
S \cdot \dot{S}<0
$$




\subsection{Fuzzy sliding mode control of the DFIG}

The disadvantage of sliding mode controllers is that the discontinuous control signal produces chattering. In order to eliminate the chattering phenomenon, we propose to use the fuzzy sliding mode control. The fuzzy sliding mode controller (FSMC) is a modification of the sliding mode controller, where the switching controller term sat $(S(x))$, has been replaced by a fuzzy control input as given below [25].

$$
U^{c o m}=U^{e q}+U^{F u z z y}
$$

The proposed fuzzy sliding mode control, which is designed to control the active and reactive power of the DFIG is shown in Figure 4. To synthesis the fuzzy controller of the two variables (active and reactive powers) fuzzy control uses a set of rules to represent how to control the system; these are the steps of fuzzification and defuzzification as shown in Table 1. The membership functions for input and output variables are given by Figure 5 .

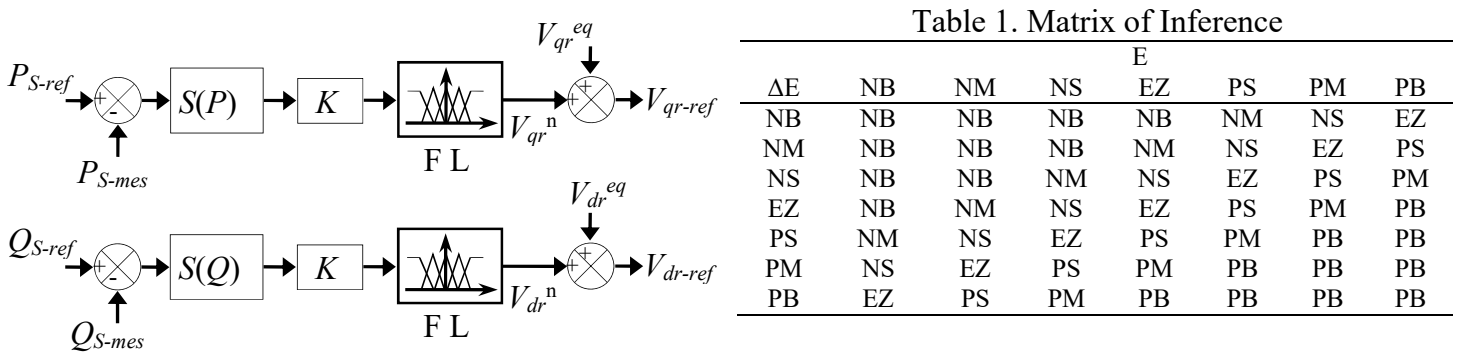

Figure 4. Bloc diagram of the DFIG control with FSMC

- NB: Negative Big,

- NM: Negative Middle,

- NS: Negative Small,

- EZ: Equal Zero,

- PS: Positive Small,

- PM: Positive Middle,

- PB: Positive Big.
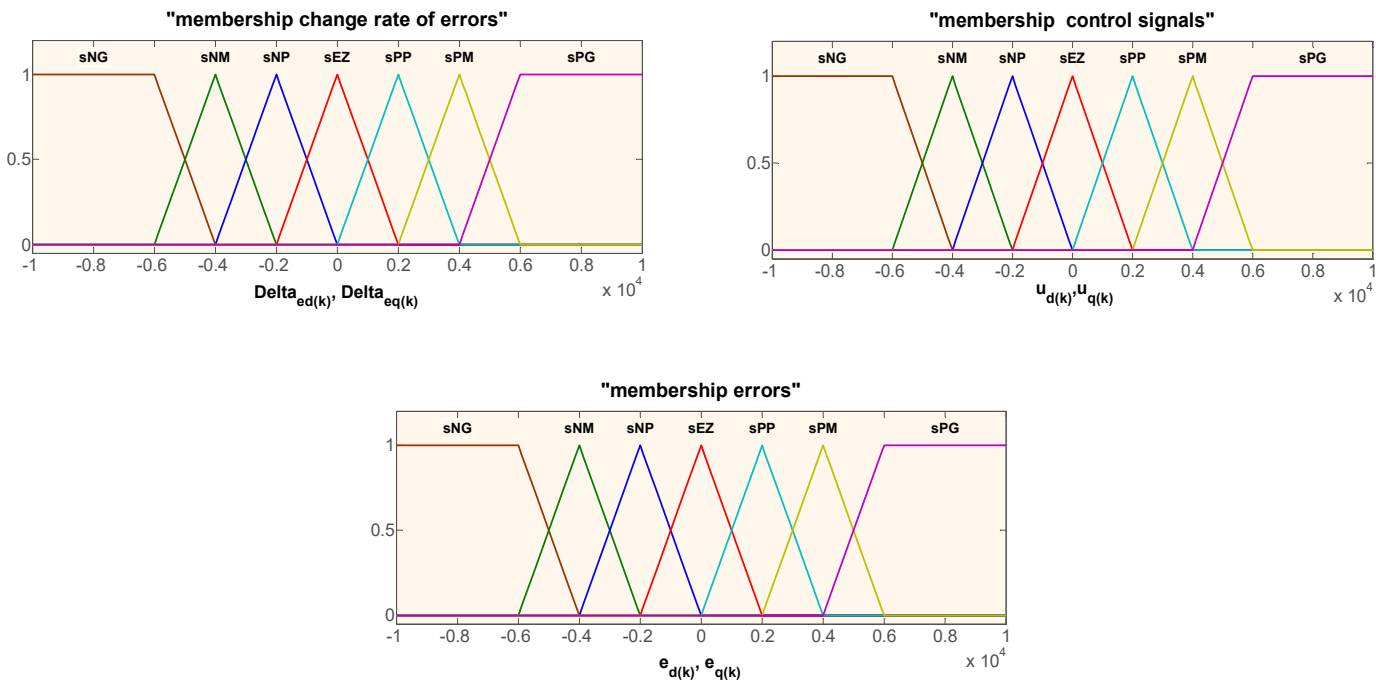

Figure 5. Fuzzy sets and its membership functions 


\section{RESULTS AND ANALYSIS}

These simulations represent a comparison between the conventional sliding mode control and the fuzzy sliding mode control.In the aim to evaluate the performances of these two controllers, three categories of tests have been realized by the simulation in Matlab/Simulink. The parameters utilized are listed in Tables 2 and 3.

Table 2. DFIG parameters

\begin{tabular}{cccc}
\hline $\mathrm{PN}=1.5 \mathrm{MW}$ & $\mathrm{Vs}=398 / 690 \mathrm{~V}$ & $\mathrm{f}=50 \mathrm{~Hz}$ & $\mathrm{~J}=1000 \mathrm{Kg} . \mathrm{m} 2$ \\
\hline $\mathrm{P}=2$ & $\mathrm{Rs}=0.012 \Omega$ & $\mathrm{Rr}=0.021 \Omega$ & $\mathrm{fv}=0.0024 \mathrm{Nm} / \mathrm{s}$ \\
\hline $\mathrm{M}=0.0135 \mathrm{H}$ & $\mathrm{Ls}=0.0137 \mathrm{H}$ & $\mathrm{Lr}=0.0136 \mathrm{H}$ & \\
\hline
\end{tabular}

Table 3. Turbine parameters Diameter $=35.25 \mathrm{~m}$

Gearbox G=90

Number of blade $=3$

\subsection{Pursuit test}

Simulation results are presented in Figures 6 and 7. As it's shown by Figure 6, for the two controllers, the stator active and reactive powers track almost perfectly their references and ensure a perfect decoupling between the two axes. Both controllers proved very good performance for this test. On the other hand, Figure 7 shows the harmonic spectrum of one phase stator current of the DFIG obtained using Fast Fourier Transform (FFT). It is observed that the FSMC is effective in eliminating chattering phenomenon.

\subsection{Sensitivity to the speed variation}

The aim of this test is to analyze the influence of a speed variation of the DFIG on active and reactive powers for the two controllers. For this objective and at time $=0.04 \mathrm{~s}$, the speed was varied from 150 $\mathrm{rad} / \mathrm{s}$ to $170 \mathrm{rad} / \mathrm{s}$. The simulation results are shown in Figure 8 . As it is shown in Figure 8, the speed variation produced a slight effect on the powers curves of the system with SMC controller, while the effect is almost negligible for the system with FSMC one. It can be noticed that this last has a nearly perfect speed disturbance rejection, indeed; only very small power variations can be observed (fewer than $2 \%$ ). This result is attractive for wind energy applications to ensure stability and quality of the generated power when the speed is varying.

\subsection{Robusness}

In order to test the robustness of the used controllers, the machine parameters have been modified: the values of the stator and the rotor resistances $R_{s}$ and $R_{r}$ are doubled and the values of inductances $L_{s}, L_{r}$ and $M$ are divided by 2 . The machine is running at its nominal speed. The results presented in Figure 10 shows that the parameters variations of the DFIG increase slightly the time-response of the two controllers. On the other hand this results show that parameter variations of the DFIG presents a clear effect on the powers curves (their errors curves) and that the effect appears more significant for SMC controller than that with FSMC one. Thus it can be concluded that this last is more robust than the classical SMC controller. We can therefore say that for the FSMC, the response time is significantly reduced and the oscillations are limited and damped more rapidly compared to SMC controller. Simulations with this type of controller presented very interesting performances in terms of reference tracking (time response, overshoot), sensitivity to perturbation.
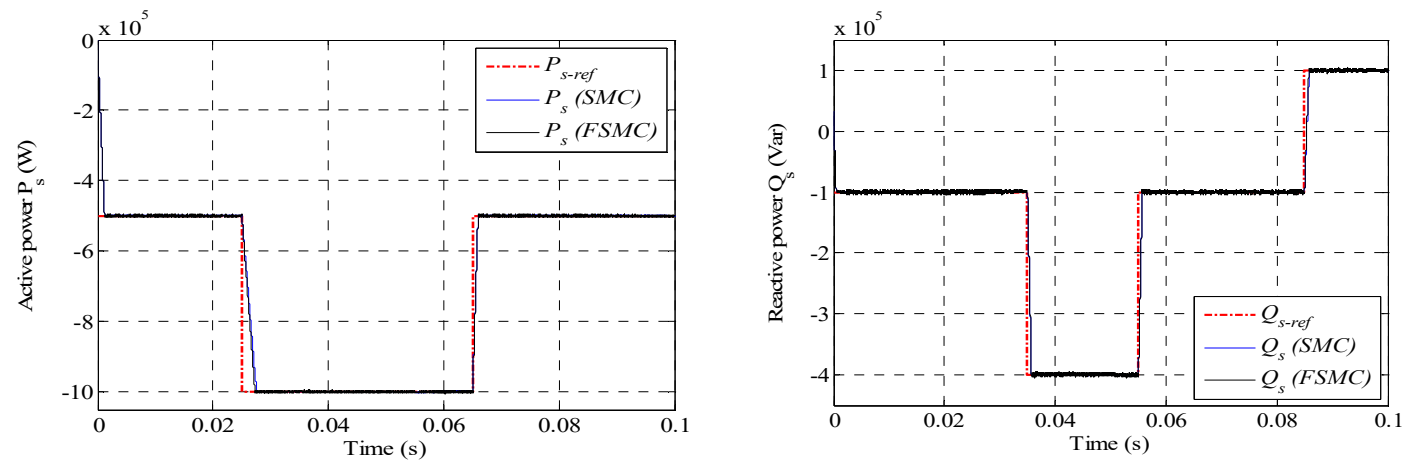

Figure 6. References tracking test 

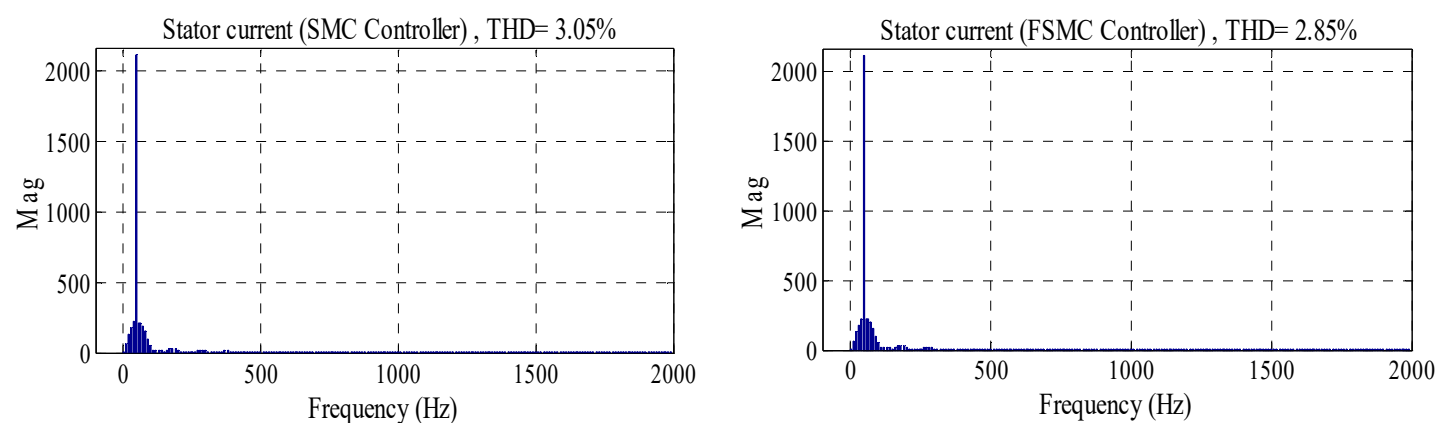

Figure 7. Spectrum harmonic of one phase stator current for SMC and FSMC controllers
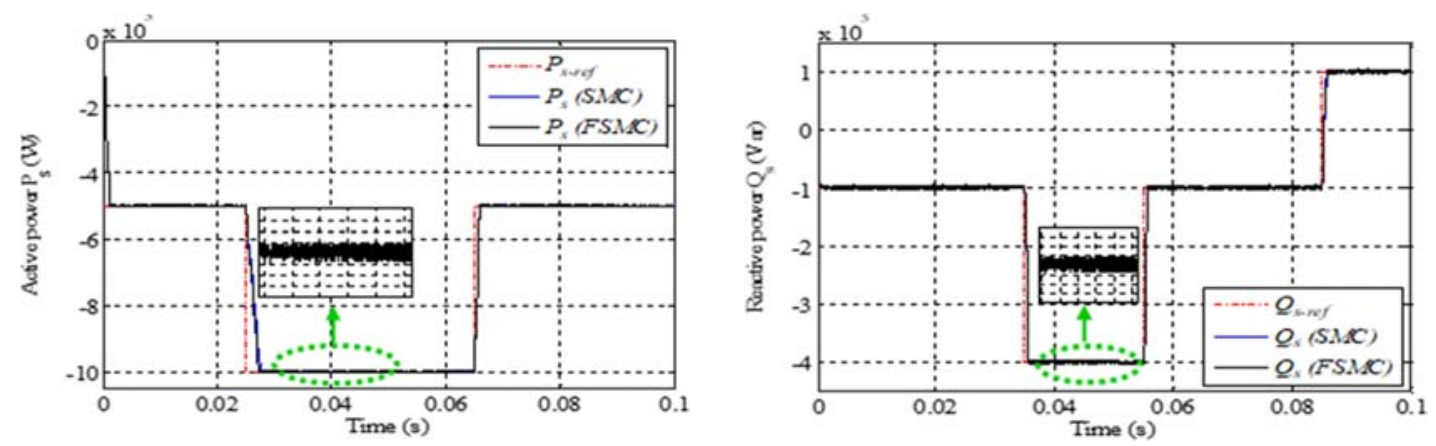

Figure 8. Sensitivity to the speed variation
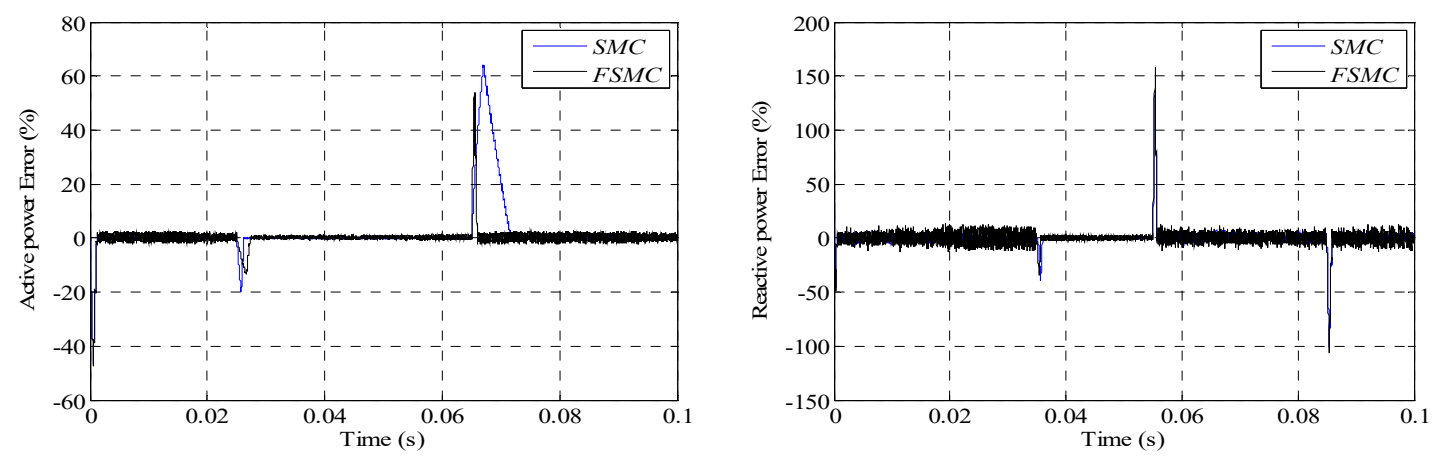

Figure 10. Robustness test

\section{CONCLUSION}

This paper presents Hybrid Fuzzy Sliding Mode Control of active and reactive power in a DFIG and performance evaluations. After presenting a description of a doubly fed induction generator, a decoupling control method of active and reactive powers for DFIG has been developed. After modeling the system, the description of the classical sliding mode controller (SMC) is presented in detail, this controller has been applied due to its excellent properties, such as insensitivity to certain external disturbances, however in standard sliding mode there is larger chattering. A hybrid fuzzy sliding mode approach using vector control strategy was established and presented. Responses of our system with this type of controller have shown that the last gives very interesting performances toward reference tracking, sensitivity to perturbation and robustness under parameters variation.

Int J Pow Elec \& Dri Syst, Vol. 10, No. 3, Sep 2019 : 1592 - 1602 


\section{NOMENCLATURE}

DFIG Doubly Fed Induction Generator

$V s, f, \mathrm{w} s, \mathrm{w}$ stator voltage, frequency grid and electrical speed, respectively

$V d s, V q s, V d r, V q r$ stator and rotor voltages in d-q reference frame, respectively

$i d s, i q s, i d r, i q r$ stator and rotor currents in d-q reference frame, respectively

$\Phi d s, \Phi q s, \Phi d r, \Phi q r$ stator and rotor flux linkages in $d$ - $q$ reference-frame, respectively

$R s, R r$ stator and rotor resistors of machine per phase, respectively

$L s, L r$ cyclic inductances of stator and rotor windings, respectively

$M$ the magnetizing inductance

$T e, T r$ electromagnetic and resistant torque

$P S, Q s$ stator active and reactive powers, respectively

SMC, FLC sliding Mode Control and Fuzzy Logic respectively

$P N, J, f v$ and $P$ Nominal Power, inertia, viscous friction and the number of pole pairs, respectively

\section{REFERENCES}

[1] A. Rahab, F. Senani, H. Benalla, "Direct Power Control of Brushless Doubly-Fed Induction Generator Used in Wind Energy Conversion System," International Journal of Power Electronics and Drive System, Vol. 8, No. 1, pp. 417-433, March 2017.

[2] K. Boulâam and A. Boukhelifa, "Fuzzy sliding mode control of DFIG power for a wind conversion system," 16th International Power Electronics and Motion Control Conference and Exposition, Antalya, pp. 353-358, 2014.

[3] Kheira Belgacem, Abdelkader Mezouar, Najib Essounbouli, "Design and Analysis of Adaptive Sliding Mode with Exponential Reaching Law Control for Double-Fed Induction Generator Based Wind Turbine," International Journal of Power Electronics and Drive System, Vol. 9, No. 4, pp. 1534-1544, December 2018.

[4] N. Zerzouri and H. Labar, "Active and Reactive Power Control of a Doubly Fed Induction," International Journal of Power Electronics and Drive System, vol. 5, pp. 244-251, October 2014.

[5] Arama Fatima Zohra, Bousserhane Ismail Khalil, Laribi Slimane, Sahli Youcef, Mazari Benyounes, "Artificial Intelligence Control Applied in Wind Energy Conversion System," International Journal of Power Electronics and Drive System, Vol. 9, No. 2, pp. 571-578, June 2018

[6] Benkahla M., Taleb R., Boudjema Z, "A new robust control using adaptive fuzzy sliding mode control for a DFIG supplied by a 19-level inverter with less number of switches," Electrical engineering \& electromechanics journal, no.4, pp. 11-19, 2018.

[7] B. Hamane, M. L. Doumbia, M. Bouhamida, M. Benghanem, "Control of Wind Turbine Based on DFIG Using Fuzzy-PI and Sliding Mode Controllers," IEEE Proceedings Ninth International Conference on Ecological Vehicles and Renewable Energies (EVER), Monte-Carlo (Monaco), French, pp. 440-448, 2014.

[8] Z. Boudjema, A. Meroufel and Y. Djeriri, "Nonlinear Control of a Doubly Fed Induction Generator for Wind EnergyConversion," Carpathian Journal of Electronic and Computer Engineering, Vol. 6, №1, pp. 28 - 35, 2013.

[9] K. Belgacem, "Sliding Mode Control of a Doubly-fed Induction Generator for Wind Energy Conversion," International Journal of Energy Engineering, vol/issue: 30(01), pp 30-36, 2013.

[10] O. Boughazi, "Sliding Mode Backstepping Control of Induction Motor," International Journal of Power Electronics and Drive System, vol/issue: 4(4), pp. 481-488, 2014.

[11] Merabet A., et al., "Implementation of sliding mode control system for generator and grid side control of wind energy conversion system," IEEE Trans Sustain Energy, vol/issue: 7(3), pp. 1327-35, 2016.

[12] Liao K., et al., "A sliding mode based damping control of DFIG for interarea power oscillations," IEEE Trans Sustain Energy, vol/issue: 8(1), pp. 258-67, 2017.

[13] H. Aschemann and D. Schindele, "Sliding-mode control of a highspeed linear axis driven by pneumatic muscle actuators," IEEE Trans. On Industrial Electronics, vol/issue: 55(11), pp. 3855-3864, 2008.

[14] B. Belkacem, "Hybrid Fuzzy Sliding Mode Control of a DFIG Integrated into the Network," International Journal of Power Electronics and Drive System, vol/issue: 3(4), pp. 351-364, 2013.

[15] S. Biricik, "Optimized Sliding mode control to maximize existence region for single-phase dynamic voltage restorers," IEEE Transactions on Industrial Informatics, vol/issue: 12(4), pp. 1486-1497, 2016.

[16] Ouassila Belounis, Hocine Labar, "Fuzzy Sliding Mode Controller of DFIG for Wind Energy Conversion," International Journal of Intelligent Engineering and Systems, Vol.10, No.2, 2017, pp.163-174, 2017.

[17] T .Mesbahi, T. Ghennam, E.M. Berkouk, "A doubly fed induction generator for wind stand $\neg$ alone power applications (simulation and experimental validation)," IEEE XXth International Conference on Electrical Machines (ICEM), Marseille, France, pp. 2028-2033, 2012.

[18] T. Ghennam, E.M. Berkouk, B. François, "Modeling and control of doubly fed induction generator (DFIG) based wind conversion system," IEEE, Second International Conference on Power Engineering, Energy and Electrical Drives (Powereng), Lisbon, Portugal, pp. 507-512, 2009.

[19] Smail Mansouri, Ali Benatillah, "Indirect Control of a Doubly-Fed Induction Machine for Wind Energy Conversion," International Journal of Power Electronics and Drive System, Vol. 4, No. 3, pp. 400-405, September 2014.

Fuzzy sliding mode control of doubly-fed induction generator driven by wind turbine (M. Benmeziane) 
[20] Zinelaabidine BOUDJEMA, Abdelkader MEROUFEL, Ahmed AMARI, "Robust Control of a Doubly Fed Induction Generator (DFIG) Fed by a Direct AC-AC Converter," PRZEGLAD ELEKTROTECHNICZNY, No/VOL: 12a/2012, pp. 213-221, 2012.

[21] S. EL-Aimani, B. Françoi, F. Minne, B. Robyns, "Modeling and simulation of doubly fed induction generators for variable speed wind turbines integrated in a distribution network," 10th European conference on power electronics

[22] Mohamed Abid, Youcef Ramdani, Abdel Kader Meroufel, "Speed sliding mode control of sensorless induction machine," Journal of Electrical Engineering, Vol. 57, No. 1, pp. 47-51, 2006.

[23] T. Sun, Z. Chen and F. Blaabjerg, "Flicker study on variable speed wind turbines with doubly fed induction generators," IEEE Transactions on Energy Conversion, pp. 896-905, 20 December 2005.

[24] Zinelaabidine Boudjema, Rachid Taleb, A. Yahdou, H. Kahal, "High order sliding mode control of a DFIM supplied by two power inverters," Carpathian Journal of Electronic and Computer Engineering 8/1, pp. 23-30, 2015.

[25] Sid Ahmed El Mahdi ARDJOUN, Mohamed ABID, Abdel Ghani AISSAOUI, Abedelatif NACERI, "A robust fuzzy sliding mode control applied to the double fed induction machine," International Journal Of Circuits, Systems And Signal Processing, Issue 4, Volume 5, pp. 315-321, 2011. 